\title{
Empowering rural women in Kerala: A study on the role of Self Help Groups (SHGs)
}

\author{
Minimol M. C. ${ }^{1 \star}$ and Makesh K. G. ${ }^{2}$ \\ ${ }^{1}$ Rajagiri Centre for Business Studies, Rajagiri Valley P. O. Kakkanad, Kochi - 682 039, Kerala, India. \\ ${ }^{2}$ School of Communication and Management Studies [SCMS], Pratap Nagar, Muttom, Aluva, Kochi - 683 106, \\ Kerala, India. \\ Accepted 12 September, 2012
}

\begin{abstract}
Self help groups (SHGs) can act as an empowerment resource centers for the women members, percolating the benefits to the society in general. Social evils like alcoholism, domestic violence against women and children, abuse and exploitation, gender bias and social exclusion are some of the areas against which the members can effectively organize and combat. Ultimately, it can come to a point where it becomes their choice whether to remain socially, economically and socially impoverished, or to organize themselves into eradicating their deprivations. The concept of self help groups was envisaged with the intent of using its potent as a powerful tool for rural poverty alleviation through rural women empowerment. It is to be specified that women empowerment per se was not the sole motive. The objectives percolated into an overall family, community and social development to be achieved initiated from and by women themselves. It is specifically against this setting that the present study was undertaken to critically evaluate the nature and extent of impact of participation in SHGs on rural women. Analysis was conducted on the extent of various levels of empowerment achieved by the members through their participation in SHGs. Personal, social, economic and financial empowerment were attempted to evaluate.
\end{abstract}

Key words: Women empowerment, self help groups, micro-credit, social security.

\section{INTRODUCTION}

Self help groups (SHGs) are becoming one of the important means for the empowerment of poor women in almost all the developing countries including India. Kerala is no exception as regards the role played by women's collectives, known by different names for emancipation and empowerment of poor women. The NGOs who are in the field of socio-economic development of the marginalised sections in the society since last four to five decades, had initially organised Credit Unions and Mahila Samajams for better participation of people in development initiatives and also for thrift and credit facilities. Since the emergence of SHG system, as per

${ }^{\star}$ Corresponding author. E-mail: minimol@rajagiri.edu. Tel: 9846329021. the initiatives of National Bank for Agriculture and Rural Development (NABARD), and directives from Reserve Bank of India (RBI), from the beginning of 1990s, most of these Mahila Samajams and credit unions have been converted into SHGs, linked them to financial institutions for better credit facilities. In Kerala, since the middle of 1990s, the State Government also took initiatives in organizing the urban poor women into neighbourhood groups (NHGs). These NHGs are recognized as SHGs by NABARD, as far as SHG-Bank linkage and credit facilities are concerned (George, 2004). Women self help groups, formed exclusively for rural women, being an effective medium for community involvement in developmental activities, can be a powerful tool for alleviating rural poverty through the empowerment of women, by freeing themselves from the clutches of usurious moneylenders. 
Hence the present study attempts to assess the role of self help groups in improving the socio-economic status of the rural women in Kerala and to study the level of empowerment achieved by rural women in Kerala through their participation in SHGs. Review of the existing literature makes it clear that research studies focusing on the impact of self help groups on rural women, especially of Kerala are rare in nature. The study was undertaken with the major objectives of identifying the level, nature and extent of personal, social, economic and financial empowerment achieved by the members of SHGs and of testing the association between group characteristics and the level of empowerment. So, the research question is to find out the extent of empowerment of SHG members and to find out the nature and level of group related and personal problems faced by the members. The hypothesis formulated for the study - There is no significant difference in the levels of various attributes related to empowerment [i] among three categories of SHGs - under Kudumbasree, NGOand other categories, and [ii] among the five categories of age groups of respondents is tested with the help of analysis of variance.

\section{REVIEW OF LITERATURE}

The brief review of literature on self help groups, presented below facilitated the streamlining of the methodology of the study.

The study Self help groups in empowering women: case study of selected SHGs and NHGs by Jaya (2002) revealed that the SHG members unanimously agreed that the most striking advantage of the SHGs was the thrift component which acted as an 'informal bank at their doorstep'. Non-availability of incentives to group leaders was identified to be the factor leading to their waning interest and the gradual decline in the functional efficiency of even the successful groups. One major impact of SHGs on the women members was the creation of awareness on newer economic opportunities available.

Anju and Sidney (2002), in their study measuring women's empowerment as a variable in international development, attempted to outline the most promising methodological approaches to measuring and analyzing women's empowerment. They review major strands of theoretical, methodological and empirical literature on empowerment from the fields of economics, sociology, anthropology, and demography, and attempt to summarize what we know and do not know about what leads to women's empowerment, and its consequences for development and poverty reduction. Based on their analysis, they provide some concrete recommendations regarding where the field stands in defining, conceptualizing, and measuring empowerment, and what might be next steps for utilizing and refining existing frameworks, collecting data and conducting analyses, and incorporating approaches from related literatures.

The report $A$ report on women self help groups in Kerala State, India: A public health perspective by Mohindra (2003) explores the linkages between microcredit through SHGs and health. The report identifies that in addition to providing opportunities to women to participate in financial activities and in expanding their social network, SHGs also generates female autonomy and solidarity which in turn leads to better health consciousness, increased access to health care services and better decision making capabilities on health of family members. Zubair Meenai (2003), in his book Empowering Rural Women: An approach to empowering women through credit-based Self Help Groups, tried to elucidate and simplify the approach to women's empowerment through credit-based self help groups, by both providing the theoretical perspectives as well as practical guidance and tips to operationalise the same. He portrayed credit-based self help groups, as an integrated approach where credit is only an entry point and an instrument to operationalise other aspects of group dynamics and management.

The MGR study covered10 different types of informal groups spread out in 3 provinces in Kenya - Nyanza, Central and Rift valley. The types of groups studied broadly included ROSCAs, ASCAs, and "other' self-help and were largely women groups though 3 mixed groups were included since male participation is growing hence the need to study resultant social dynamics. The overall research goal was to understand the functions, social dynamics and cultures of MGR groups in different parts of Kenya over and above money flow and other financially related information. NoRA's goal is to use the findings of this study to guide development of mobile tools and sustainable business models that can successfully link the different groups despite existing cultural and lingual barriers. Research questions were therefore developed around functions of MGRs, skills and knowledge in groups, social dynamics in and between groups, hopes and aspirations, social hierarchies, money flow and media and communication practices. Qualitative interviews and observations with different group members, their families and KIls in their respective communities were used to collect the data. The findings reveal a great deal of information about each of the 10 groups as far as the nature of the communities the groups operate in, the type of members they have, what activities they engage in as individuals and as groups, membership motivations, group operations, challenges and other dynamics.

George (2004) in his research work, A comparative study of self help groups (SHGs) organised and promoted by non governmental organisations (NGOs) and Kudumbasree - a Government Organised Non 
Governmental Organisation (GONGO) in Kerala, towards empowerment of poor women made a comparative study of the enabling processes and efforts by the NGO and Kudumbasree towards social, economic and political empowerment of poor women since last few years in Kerala.

Sakuntala (2005), in her book Empowering women: An alternative strategy from rural India, pointed out that the more vital inhibiting factors leading to the disadvantaged position of women are their ignorance, powerlessness and vulnerability. She emphasized the need for bringing about an attitudinal change among women as the most important step towards empowerment.

The study " $A$ comparative study of self help groups organized and promoted by non-governmental organisations and Kudumbasree"- A government organised non-governmental organisationin Kerala, towards empowerment of poor women by Loyola extension services found that there were visible changes in role of women in decision-making after becoming the members of SHGs. Majority of the members continued to depend on moneylenders due to insufficiency in SHG credit. SHGs were found to be effective means for encouraging poor women to participate actively in political activities and in improving their general skills.

The study Perception of officials about self help groups involved in vegetable cultivation by Sreedaya et al. 2001 identified that the officials perceived that SHGs created a sense of group cohesion, boosted self confidence, created interdependence and mutual trust among members and enhanced income generation opportunities. It was also found that involvement of members in decision-making was the least perceived one among the officials.

Eswar and Patnaik (2006), in his study empowerment of women in Orissa: A case study of Koraput district, tried to reveal the contribution of women to the development of a rural economy in a hilly and inaccessible region. The study concentrated on three areas such as education, work participation rate and agriculture for empowering women.

Rajan (2006), in his article women self help groups innovations in financing the poor, tried to analyse the significance of women empowerment and rural credit in Orissa through SHGs and also the manner of mobilization and management of thrift of SHGs in Orissa. $\mathrm{He}$ found out that the amount of thrift mobilized by women $\mathrm{SH}$ in Orissa is very meager.

Ramesh (2006), in his article Women SHGs in Orissa - a crusade for women empowerment, highlighted the role of women SHGs for women empowerment through the provision of easy credit delivery system. He presented the meaning and genesis of SHG and its development, its working pattern, linkage with formal financial institutions and its role for uplifting the women folk.

Umesh CP (2006), in his case study significance of women empowerment and rural credit in Orissa through SHGs concluded that SHGs have proved that they could bring about a change in the mindset of the very conservative and tradition bound illiterate women in rural areas. With appropriate market support strategies the members could effectively build enterprises as a source of their employment and income.

Ganesamurthy VS (2007), in his edited volume book India: Economic Empowerment of Women, reveled that in India the work participation rate of women is less than half that of women. Despite efforts made towards economic empowerment of women, majority of the active female population continues to be confined to micro, small-scale enterprises and informal sector.

Susanta et al. (2007) in their research paper, WSHG: A vehicle for women self reliance presented the success story of some women SHGs in Ganjam district of Orissa. They discussed the functioning of these SHGs and the future plans to strengthen them by introducing web-based applications for better dissemination of information regarding their products and performance.

Sudha (2008), in her book women's empowerment in South Asia, explained women's empowerment as the ability of women to transform economic and social development when empowered to fully participate in the decisions that affect their lives through leadership training, coaching, consulting and the provision of enabling tools for women to lead within their communities, regions and countries.

Khari (2009), in his study women empowerment in India tried to explore how CRTC, a relatively small isolated rural NGO in the foothills of the Himalayas, has been successful in the empowerment of rural women living in highly patriarchal and traditional societies.

BL Centre for Development Research and Action (2009), in a study titled, Micro Finance and Empowerment of Scheduled Caste Women: An Impact Study of SHGs in Uttar Pradesh and Uttaranchal found out that SHG's can contribute to overcome exploitation, create confidence for the economic self-reliance of the rural poor, particularly among women who are mostly invisible in the social structure.

\section{Statement of the problem}

Self-help groups (SHGs) or thrift and credit groups are mostly informal groups whose members pool savings and re-lend within the group on rotational or needs basis. These groups have a common perception of need and impulse towards collective action. Many of these groups got formed around specific production activity, promoted savings among members and use the pooled resources to meet emergent needs of members, including consumption needs. Women self help groups, formed exclusively for rural women, being an effective medium for community involvement in developmental activities, 
can be a powerful tool for alleviating rural poverty through the empowerment of women, by freeing themselves from the clutches of usurious moneylenders. Hence the present study attempts to assess the role of self help groups in improving the socio-economic status of the rural women in Kerala and to study the level of empowerment achieved by rural women in Kerala through their participation in SHGs. Review of the existing literature makes it clear that research studies focusing on the impact of self help groups on rural women, especially of Kerala are rare in nature. It is specifically against this setting that the present study was undertaken to critically evaluate the role-played by the SHGs in imparting social, economic, financial and personal empowerment to the rural women.

\section{Objectives of the study}

The present study was undertaken with the following objectives:

1. To identify the profile of the SHGs and its members.

2. To identify the level of personal, social, economic and financial empowerment achieved by the members of SHGs.

3. To identify the nature and extent of group-related and personal problems faced by the members of SHGs.

4. To test the association between group characteristics and empowerment.

\section{METHODOLOGY OF THE STUDY}

Exploratory research design is used for the study. The study was undertaken during the period of June 2010 to June 2011. Population for the study constitutes the entire women folk in rural Kerala, who are the members of self help groups. The sample respondents were selected by using multi-stage, stratified, judgment sampling technique.

In the first stage, the entire state of Kerala is divided into 14 revenue districts. The district of Alappuzha was selected from the entire set of districts. From the selected district, which has 2 divisions [Alapuzha and Chengannur], Alapuzha sub-division was selected, confining the study to the three [Ambalapuzha, Cherthala and Kuttanad] of the total six taluks in the district. From the three selected taluks, Cherthala taluk with 20 villages was selected. Three villages were selected to form the locale of the present study. The three villages were Kuthiathodu, Thuravoor South and Aroor. Thus the study was narrowed down to the various women-self help groups formed and functioning within the locale.

Giving due consideration to important facts like category [on basis of formation of SHG], conduct of commercial activities [groups conducting and not conducting activities], representativeness of different religious community of the locale population etc, 18 self help groups were finally selected, on stratified sampling basis, as final sample groups. Three strata into which groups were divided included groups sponsored by Kudumbasree, groups sponsored by NGOs, and groups sponsored by other types [religious, caste, local movements etc.]. There were 5 groups under Kudumbasree category, 7 under NGO-sponsorship and 6 under the other category.

Attempt was made to elicit response from all the members of the selected 18 SHGs. However, in very rare cases, where members were not accessible after repeated attempts, one or two members were dropped from the list of respondents. Accordingly, the number of respondent members was 64 from the first strata, 67 from the second and 71 from the third, totaling 202. Two responses [one each from the first and second strata] were excluded from analysis for being incomplete. Thus, the final sample size came to 200, made up of 63,66 and 71 respondents from the three strata.

\section{Sources of data}

The study predominantly depends on primary data. The data were collected from the sample of 200 members of 18 SHGs located within three villages of Cherthala Taluk of Alapuzha district in Kerala.

\section{Tools for collection of data}

Primary data were collected by employing a structured interview schedule. Besides this, participative observation, and direct personal discussions were conducted with the members of various SHGs, in order to get a clearer picture of the real situation.

\section{Pretest of tool for collection of data}

The interview schedule was pre-tested on an initial sample of 20 members for validity and consistency. The initial sample was later included in the final sample.

\section{Tools for analysis of data}

The tools of analysis used were mean score, T-Test, ANOVA and SOMER'S D Test. Mean score was employed to identify the levels of various attributes on a five-point scale. Mean score of one denotes the least level of opinion [on empowerment, problems, extent on activities etc.] which increases to subsequent levels, with five denoting the highest level of opinion. T-Test was employed to identify the statistical difference in levels of opinion on various attributes between two types of SHGs - those carrying on commercial activities and those not carrying on any commercial activities. ANOVA test was employed to identify the significance of statistical difference in levels of various attributes [i] among three categories of SHGs - under Kudumbasree, NGO and other categories, and [ii] among the five categories of age groups of respondents. SOMER'S D Test was employed to identify the statistical significance of relation [association] between the levels of empowerment on various attributes and group characteristics.

\section{Definition of certain terms used in the study}

Cohesion: A bond that links the group members together, which results from a deep sense of belonging to the group as a whole.

Social justice: Creating a group based on the principles of equality and solidarity that understands and values human rights and that recognizes the dignity of every human being.

Equality: Equality signifies correspondence between a group of different objects, persons, processes or circumstances that have the same qualities in at least one respect, but not all respects, that is, regarding one specific feature, with differences in other features. Empowerment: The process by which people negotiate a more 
equitable distribution of power, a greater space in the initial decision making process in the home, in the community and in economic and political life. It is defined as the process by which people gain greater control over material and intellectual resources overall empowerment can be described from four different dimensions such as economic, social, political and legal empowerment.

Development: Improvement in various aspects of life at individual or societal level.

Kudumbasree: Launched by the Government of Kerala in 1998 for wiping out absolute poverty from the State through concerted community action under the leadership of Local Self Governments. The mission aims at the empowerment of women, through forming self help groups and encouraging their entrepreneurial or other wide range of activities.

Chikun Gunia: A disease caused by insect-borne virus, of the genus Alphavirus, that is transmitted to humans by virus-carrying Aedes mosquitoes.

\section{RESULTS}

The profile of the members based on the category of the SHGs was identified. The different categories of groups, sponsors and conduct of any commercial activity were investigated.

\section{Category of SHGs}

The total number of SHGs covered under the study is 18 , and the total number of members covered as respondents are 200. The sample of SHGs was constructed by five groups under the Kudumbasree, seven were sponsored by various NGOs, Matsyafed being one major sponsor, and six from the other category. Others include SHGs formed under the aegis of SNDP [Sree Narayana Dharma Paripalana Yogam], KPMS [Kerala Pulayar Maha Sabha], Churches, Wincentre, ICDS etc., relating to communities and local movements. The sample of respondents drawn was 63 from Kudumbasreesponsored, 65 from NGO-sponsored and 72 from Otherssponsored SHGs.

\section{Group characteristics and nature of activities of SHGs}

Group characteristics attempted to be identified were mutual trust, cohesion, transparency, interaction, leadership, accountability, co-operation, equality, interdependence and satisfaction among members. Nearly 60 to $70 \%$ of members opined that these characteristics existed at high levels [on a five-point scale from very high to very low]. The highest level of existence was accountability and interdependence amongst members, followed by a sense of equality. Transparency in activities and accounts seemed to be eth least existing of the characteristics along with cohesion and interaction among members. Since one of the important objectives behind SHG activities is extra revenue generation, lack of transparency in activities and books of accounts can be a major worrying factor that can insinuate resentment and dissatisfaction among members. In group-wise comparison, it was found that levels of transparency were the lowest among the NGO-sponsored groups, irrespective of whether or not commercial activities were undertaken.

Almost all groups reported very low levels of activities related to dispute resolution, social justice causes and legal initiatives. Political participation and campaigns, though in poor levels, were existent. On every important fact that comes out is that the relevance and utility of micro-credit facilities and bank-linkages were grossly neglected and not mad use of. Low levels of education of members can be a very crucial factor here. It was found from the study that members who were comparatively better educated were more realistic of the existence of micro-credit and bank-linkage facilities than their less educated counter parts. Instances of use of credit facilities for financing commercial activities were very rare and low in quantity. Acquisition of lands on lease-hold for agricultural activities was even more scanty, where such possibilities exist in huge proportions. Probably, the members need more guidance and confidence build-up before they consider themselves competent enough to take up such risks.

Collective production / manufacturing was also very less. Those engaged in such activities limited themselves to the very typical pickle, soap-powder, dried fish etc. in the initial stages, there used to be more reported instances of umbrella manufacturing, note book manufacturing etc., which eventually died out, on concerns of cost affordability and marketing difficulties. Incapacity to enter in to a competitive market is awfully evident.

\section{Personal empowerment of members}

Self respect and mutual respect were the ones among the personal empowerment [general] attributes which was reported with highest level of empowerment (Table 1). All other attributes like confidence, independence, and acceptance among relatives/family also recorded high level of empowerment. The sense of achievement among the members in undertaking some activities related to the groups were evident. For instance, weekly deposits and personal loans taken from the group corpus necessitate weekly calculation of interest rates, which can be a demand for a rural woman. Though the time taken for such calculations can gobble up substantial part of the meeting time, the sense of achievement and elation that the members - treasurer in particular - feel at the end is worth acknowledgement. To a larger extent, it has to be acknowledged that the society has come to accept the 
Table 1. Personal empowerment [general attributes] [figures in percentages].

\begin{tabular}{|c|c|c|c|c|c|c|}
\hline \multirow{2}{*}{ Personal empowerment attribute } & \multicolumn{5}{|c|}{ Level of personal empowerment } & \multirow{2}{*}{ Mean score } \\
\hline & Very high & High & Moderate & Low & Very low & \\
\hline Confidence & 9 & 84 & 4 & 1 & 2 & 3.97 \\
\hline Independence & 7 & 85 & 6 & 2 & & 3.96 \\
\hline Self respect & 8 & 88 & 3 & 1 & & 4.03 \\
\hline Mutual respect & 9 & 83 & 5 & 2 & 1 & 4.00 \\
\hline Family acceptance & 12 & 72 & 11 & 4 & 1 & 3.91 \\
\hline Relatives acceptance & 15 & 65 & 14 & 5 & 1 & 3.90 \\
\hline Average & 10 & 79 & 7 & 3 & 1 & 3.96 \\
\hline
\end{tabular}

Source: Survey results.

Table 2. Social empowerment [figures in percentages].

\begin{tabular}{lcccccc}
\hline \multirow{2}{*}{ Social empowerment attribute } & \multicolumn{5}{c}{ Level of social empowerment } & \multirow{2}{*}{ Mean score } \\
\cline { 2 - 6 } & Very high & High & Moderate & Low & Very low & \\
\hline Organizational skill & 1 & 3 & 34 & 41 & 22 & 2.18 \\
Group cohesiveness & 1 & 4 & 32 & 51 & 12 & 2.31 \\
Interactive skills & 1 & 7 & 28 & 44 & 19 & 2.28 \\
Public speaking & & 5 & 19 & 35 & 46 & 2.02 \\
Awareness on rights & & 2 & 19 & 47 & 32 & 1.88 \\
Acceptance in society & & 4 & 18 & 38 & 40 & 1.91 \\
Awareness on social problems & & 2 & 13 & 31 & 54 & 1.63 \\
Participation in social programmes & 15 & 5 & 7 & 4 & 69 & 1.93 \\
Membership in other organizations & 2 & 4 & 21 & 36 & 36 & 2.00 \\
Average & &
\end{tabular}

Source: Survey results.

women's organized movement as a part of the social establishment. When week-end evening meetings of the group is convened in any member's home, the other family members - particularly male members - do show up very little resentment over the inconveniences so caused.

\section{Social empowerment of members}

Rural women were generally found to be least participative in social programmes. Awareness on rights / social problems still was very low. Not limiting itself to the conduct of formalities of meetings and activities, the groups are expected to provide a very effective platform for women to discuss among themselves, their problems, solutions and aspirations. In many cases, it was found that the members themselves felt that the group meetings were proving to be futile grounds for empowering them form a social perspective. For instance, many members confided that they never discussed issues like dowry, alcoholism etc. within the group, though they personally felt the impressions of these vices in life is very marked and indelible. The group activities were found to be effective at low levels in spheres that were very closely tied to such activities - capacity to organizing activities, group cohesiveness, interactions and public speaking. This readily points out to the fact that social empowerment (Table 2) is an area where these groups and its activities poorly caters to. Members reported very low levels of participation in social programmes. There were reports of members involved in more than one group.

\section{Economic empowerment of members}

There have been extensive discussions by experts and theorists on the potential of SHGs in creating employment opportunities to the members directly or indirectly. Groups that undertake commercial activities can provide direct employment, whereas others can create employment opportunities by providing some training on technical or entrepreneurial skills. On aspects of creating employment opportunities for the members, or in providing enhancements in technical or entrepreneurial 
Table 3. Level of economic empowerment [figures in percentages].

\begin{tabular}{lcccccc}
\hline \multirow{2}{*}{ Economic empowerment attribute } & \multicolumn{5}{c}{ Level of economic empowerment } & \multirow{2}{*}{ Mean score } \\
\cline { 2 - 6 } & Very high & High & Moderate & Low & Very low & \\
\hline Employment opportunity & 1 & 5 & 4 & 13 & 77 & 1.40 \\
Technical skill & & & 2 & 4 & 94 & 1.08 \\
Entrepreneurial skill & & 3 & 4 & 12 & 81 & 1.29 \\
Individual/family health & 16 & 25 & 56 & 2 & 1 & 3.53 \\
Living conditions & 3 & 31 & 64 & 1 & 1 & 3.34 \\
Economic status & 1 & 18 & 74 & 5 & 2 & 3.11 \\
Social security & & 6 & 68 & 22 & 4 & 2.76 \\
Average & 3 & 13 & 39 & 8 & 37 & 2.36 \\
\hline
\end{tabular}

Source: Survey results.

Table 4. Level of financial empowerment [figures in percentages].

\begin{tabular}{llllllll}
\hline \multirow{2}{*}{ Financial empowerment attribute } & \multicolumn{9}{l}{ Level of financial empowerment } & \multirow{2}{*}{ Mean score } \\
\cline { 2 - 6 } & Very high & High & Moderate & Low & Very low & \\
\hline Income & & 6 & 72 & 21 & 1 & 2.83 \\
Savings & 1 & 5 & 8 & 68 & 19 & 1.99 \\
Expenditure & 1 & 30 & 38 & 24 & 7 & 2.94 \\
Financial management skills & 6 & 30 & 47 & 16 & 2.29 \\
Personal belongings & & 3 & 6 & 18 & 73 & 1.39 \\
Financial security & 3 & 7 & 11 & 21 & 58 & 1.76 \\
Average & 1 & 10 & 28 & 33 & 29 & 2.20 \\
\hline
\end{tabular}

Source: Survey results.

skills, it was found that the groups fared awfully badly. Very minimal number of members felt improvements in their employment opportunities and skills. Improvement in health was one area in which nearly high level of empowerment was achieved Table 3. In rural areas, primary health centers [PHCs] play a very vital role in catering to the basic health requirements of the society. In the wake of the Chikun Gunia [a disease found in rural coastal areas of Kerala] and its aftermath, significance of these centers have increased. Rural medical camps and awareness programmmes conducted are usually well attended by the rural women folk. Often, SHGs act as facilitators for such programmes. It can be a reason for the reported empowerment in individual/family health.

\section{Financial empowerment of members}

Nearly three-fourth of the members reported moderate levels of empowerment in income levels (Table 4) whereas it was almost nearly offset by low improvement in savings. The only direct reason for reduced capacity for savings is seen to be higher level of increase in expenditure. $[\mathrm{Ab}]$ use of mobile phones was fervent. Many of the members admitted that their expenditures on mobile phones had gone up considerably. Invariably, level of empowerment in financial management skills was low. Personal belongings, except for mobile phones again, represented very low level of improvement. It is also been proved that the rural women had failed to enrich themselves with a feeling of financial security through their association with SHGs.

\section{Group-related problems faced by members}

Various problems related to group was evaluated for existence. Barriers in activities, drop-outs, conflicts, nontransparency etc. can be examples.

Group-related problems were reported to be low (Table 5). Among the problems that were existent, conflicts between members and absenteeism from meetings were reported by nearly $15 \%$ members. Irregular meetings, improper records, non-accessibility to records, no internal audit and pressure groups were testified at low level of existence.

\section{Personal problems faced by members}

Personal problems, in addition to group-related ones, 
Table 5. Group-related problems faced [figures in percentages].

\begin{tabular}{lcccccc}
\hline \multirow{2}{*}{ Group-related problems faced } & \multicolumn{5}{c}{ Opinion on level of problems faced } & \multirow{2}{*}{ Mean score } \\
\cline { 2 - 6 } & Very high & High & Moderate & Low & Very low & \\
\hline Non-sustainability of future activities & 0 & 2 & 0 & 3 & 95 & 1.09 \\
Entry barriers & 0 & 2 & 0 & 1 & 97 & 1.07 \\
Operational barriers & 1 & 2 & 0 & 2 & 95 & 1.12 \\
Drop-outs & 0 & 6 & 1 & 0 & 93 & 1.20 \\
Conflicts in group & 2 & 14 & 1 & 1 & 82 & 1.53 \\
Absenteeism & 1 & 14 & 3 & 2 & 80 & 1.54 \\
Irregular meetings & 0 & 1 & 0 & 28 & 71 & 1.31 \\
Improper records & 0 & 1 & 0 & 29 & 70 & 1.32 \\
Non-accessibility to records & 0 & 1 & 2 & 24 & 73 & 1.31 \\
No internal audit & 0 & 3 & 1 & 20 & 76 & 1.31 \\
Pressure groups & 0 & 1 & 2 & 22 & 75 & 1.29 \\
Non-transparent activities & 0 & 0 & 3 & 16 & 81 & 1.22 \\
Average & 0 & 4 & 1 & 12 & 82 & 1.28 \\
\hline
\end{tabular}

Source: Survey results.

Table 6. Extent of personal problems faced [figures in percentages].

\begin{tabular}{lcccccc}
\hline \multirow{2}{*}{ Personal problems faced } & \multicolumn{5}{c}{ Level of personal problems faced } & \multirow{2}{*}{ Mean score } \\
\cline { 2 - 6 } & Very high & High & Moderate & Low & Very low & \\
\hline Family responsibilities & 80 & 16 & 1 & 3 & & 4.73 \\
Job responsibilities & 1 & 8 & 1 & 15 & 75 & 1.45 \\
Low economic status & 3 & 15 & 71 & 10 & 1 & 3.09 \\
Low motivation & & 7 & 80 & 11 & 2 & 2.92 \\
Lack of family support & 10 & 28 & 48 & 14 & & 3.34 \\
Low benefits from group & 1 & 9 & 25 & 44 & 21 & 2.25 \\
Low general knowledge & & 1 & 22 & 20 & 57 & 1.67 \\
Average & 14 & 12 & 35 & 17 & 22 & 2.78 \\
\hline
\end{tabular}

Source: Survey results.

faced by the SHG members were enquired into for existence Table 6. Family and job responsibilities can cause difficulties for active participation in group activities. Low levels of motivation and family support can also act as a deterrent. Low economic status and poor benefits form group can shun members from reaping the benefits of being in the group. Family responsibilities [mean score of 4.73] proved to be the major difficulty faced by the members in their group activities. Job responsibilities do not cause difficulties, due to the fact that majority are unemployed. Low economic status [3.09] and low motivation [2.92] were opined to be causing moderate problems. One very important reason faced as difficulty was low family support [3.34]. Among the respondents, a tall proportion of $38 \%$ experienced high/very high levels of poor family support. An overall perusal of problems faced by group members reveal that conflicts among members, absenteeism, family responsibilities and lack of family support were the major ones that can potentially impede the attainment of group objectives.

\section{Association between empowerment and group characteristics}

Groups exhibited characteristics like mutual trust, cohesion, transparency, leadership, etc at different levels. Somer's D Test was employed to identify whether the various empowerment levels achieved by members were associated with group characteristics displayed. The test reveals the direction [positive or negative relation], strength [weak, low or strong] and significance of relation that exist between the two sets of variables.

Positive relations are denoted by positive symbol $[+]$ and negative relations by negative symbol [-]. The 
various levels of strength of relationship in ascending order were very weak, weak, very low, low, moderate, high, very high, strong, and very strong.

\section{Association between personal empowerment and group characteristics}

All personal empowerment variables [Confidence, independence, self-/mutual respect, family/relatives acceptance] exhibited a positive low association with mutual trust between the group members. The relation was statistically significant at $95 \%$ level of confidence. Cohesion had a weak to low levels of positive association between different empowerment variables, and the association was statistically significant. Transparency's association with confidence and self-respect was weak and statistically not significant. Leadership, accountability, satisfaction and co-operation had weak and statistically significant association with empower-ment. Interdependence exerted a moderate association with self/mutual respect. Overall it is found that there existed only weak/low/very weak/very low [moderate levels included, but very sparsely] levels of association between personal empowerment and group characteristics

\section{Association between social empowerment and group characteristics}

As seen, majority of the relations are negative in direction. It is also evident that all relations are either weak or very weak, with instances of zero relations as well. In very sparse cases, the association turned out to be statistically significant. Organizational skills had no relation with mutual trust, and except for accountability, interdependence and satisfaction, other relations were negative, none exhibiting statistical significance. Group cohesiveness was very weakly related to group characteristics, with positive relation only with accountability and interdependence. Public speaking exhibited negative relations with all characteristics, with weak relation with mutual trust proving to be significant. Acceptance in society was negatively related except to accountability. Participation in social programmes had no statistically significant relations with group characteristics, but exhibited positive weak relations with leadership and accountability. Membership in other organizations had weak positive relations to most group characteristics, but for negative relations with cohesion and transparency.

\section{Association between economic empowerment and group characteristics}

Economic empowerment variables were found to be weakly/very weakly associated with group characteristics, with low instances of negative relations and very sparse cases of statistically significant ones. Empowerment in employment opportunity and entrepreneurial skills was found to be substantially negatively associated with group characteristics. Living conditions, economic status and social security showed positive association. Health was negatively related to leadership alone. The low association of social security with equity and satisfaction was found to be statistically significant.

\section{Association between financial empowerment and group characteristics}

It is seen that a substantial majority of the association was very weak in nature with limited cases of weak relations. Instances of statistical significance of association were found to be very limited. Except for few instances, all associations were positive in its direction. Empowerment in income was positively associated with cohesion, transparency, accountability, co-operation and interdependence, unrelated to equality and negatively to others, though none of these were found to be statistically significant. Empowerment in savings was very weakly associated with all variables of characteristics, with equal number of negative and positive relations. The weak association of expenditure was found to be statistically significant with leadership, accountability, mutual trust, interdependence and satisfaction. Empowerment in financial management skills was found to have significant association with cohesion, transparency, interaction, leadership, co-operation, interdependence and equality. Empowerment in personal belongings was found to be negatively related to transparency, accountability, co-operation and interdependence, though none of the relations were significant. Improvement in financial security was found to be very weakly associated with all group characteristics, with relations to cohesion, equality and satisfaction being negative in direction.

\section{DISCUSSION}

In group-wise comparison, it was found that levels of transparency were the lowest among the NGOsponsored groups, irrespective of whether or not commercial activities were undertaken. Almost all groups reported very low levels of activities related to dispute resolution, social justice causes and legal initiatives.

Self respect and mutual respect were the ones among the personal empowerment [general] attributes which was reported with highest level of empowerment. All other attributes like confidence, independence, and acceptance among relatives/family also recorded high 
level of empowerment.

The group activities were found to be effective at low levels in spheres that were very closely tied to such activities - capacity to organizing activities, group cohesiveness, interactions and public speaking. This readily points out to the fact that social empowerment is an area where these groups and its activities poorly caters to. Members reported very low levels of participation in social programmes.

Very minimal number of members felt improvements in their employment opportunities and skills. Improvement in health was one area in which nearly high level of empowerment was achieved.

Nearly three-fourth of the members reported moderate levels of empowerment in income levels whereas it was almost nearly offset by low improvement in savings. The only direct reason for reduced capacity for savings is seen to be higher level of increase in expenditure.

Major among the problems faced were found to be absenteeism and conflicts among members. There existed few instances of drop-outs and lack of internal audit. There was a case reported of a SHG, which had to be wound up, on reasons of conflicts among the members and the resultant absenteeism and drop-outs.

Family-related responsibilities were found to be most prevalent among the personal problems faced by the members. Next in importance was lack of family support. Though the male members in the family had ceased to be resistive towards their women folk being part of SHGs, they were never proactively supportive. Low economic status and low motivation along with low benefits from the group proved to be important problems.

There is the need for the basic nature of SHG and its related activities for a re-think. It is time to realize where things have gone wrong, or if not, where things were not so right. The following are suggested as ameliorative:

i. Intellectual empowerment is to be considered more important, or at least equally important to social, economic or financial empowerment. The concept of personal empowerment often fails to encompass intellectual empowerment. The objective intended to be achieved is that the members become more capacitated to think and act better - from blunt in thinking to sharp; and from thick in action to fine.

ii. Meetings of SHGs are suggested to widen in its scope. At present, though the conduct of meetings is almost mandatory, the proceedings lack a constructive agenda. Meetings should have pre-prescribed agenda, aimed at achieving intellectual empowerment. Discussions should ideally include concurrent topics in the social, economic or political environment.

iii. It is also worth consideration, acceptance of some prominent senior personalities, as the mentors of the group. They can attend the meetings of the group and control and guide the proceedings to be meaningful. Also, these mentors can enlighten the members on the finer and broader aspects of current topics taken up for discussions. Attainment of intellectual empowerment can thus be facilitated.

iv. Members, younger members in particular, need to be taught on the importance of financial security. The absence of savings habit in the younger members, and the general dependence on informal savings methods are alarming.

v. Employability of rural women is very poor. It is evident form the very scarce number of members who are salaried and income generating. Measures can be adopted to impart technical/professional training to members to enhance skills. Though it can be expensive, assistance of local authorities, professional/technical educational institutions etc. can be approached for assistance.

vi. Social activities of the groups are found to be very scanty. It is highly imperative that groups initiate participation in social activities more actively. SHGs can gain immensely by becoming a stakeholder in the society.

vii. Commercial activities undertaken by the groups in general are found to be very narrow. Typical marketing and processing activities are pursued. SHGs should think of looking at broader types of activities.

viii. In almost all cases, it was found that the commercial activities undertaken, either dies out, or remains at the same level, without achieving any improvements in operational efficiency. Income potential of existent activities are very limited. Improvements in skills and training can ensure enhanced viability and profitability of commercial activities.

ix. Lack of family support is still evidenced as a problem faced by members. The group by itself can collude the efforts of the members in coordinating activities aimed at ensuring better support from family members.

\section{Conclusion}

Thus, it is concluded that the concept of SHGs for rural women empowerment has not yet run its full course in attaining its objective. Further efforts in refining group characteristics and realigning group objectives can ensure furtherance of effectiveness of SHGs in translating rural women into a more powerful section of the society.

\section{REFERENCES}

Anju M, Sidney RS (2002). Measuring Women's Empowerment as a Variable in International Development, World Bank Workshop on Poverty and Gender: New Perspectives pp.10-50.

BL Centre for Development Research and Action (2009). "Micro Finance and Empowerment of Scheduled Caste Women: An Impact 
Study of SHGs in Uttar Pradesh and Uttaranchal", retrieved from planningcommission.nic.in/reports/sereport/ser/stdymcrofin on 30 June.

Eswar R, Patnaik B (2006). "Empowerment of Women in Orissa: A Case Study of Koraput District", Women Empowerment, Panigrahy R.L, Dasarathi Bhuyan, Discovery Publishing House, New Delhi pp.43-56.

Ganesamurthy VS (2007). India: Economic Empowerment of Women, New Century Publications, New Delhi pp.87-102.

George MK (2004). A Comparative Study of Self Help Groups (SHGs) Organised and Promoted by Non Governmental Organisations (NGOs) and Kudumbasree - A Government Organised Non Governmental Organisation (GONGO) in Kerala, Towards Empowerment of Poor Women, Loyola Extension Services, Loyola College of Social Sciences, Sreekariyam, December 2004.

Jaya SA (2002). Self-Help Groups in Empowering Women: Case Study of Selected SHGs and NHGs, Discussion Paper, Kerala Research Programme on Local Level Development Centre for Development Studies, Thiruvananthapuram pp.65-120.

Khari DS (2009). Women Empowerment in India, ALP Books, New Delhi.

Mohindra KS (2003). A Report on Women Self Help Groups (SHGs) in Kerala State, India: A Public Health Perspective, March, retrieved from http://www.cacis.umontreal.ca on 30 June 2009.

Rajan KS (2006). "Women Self Help Groups - Innovations in Financing the Poor", Self Help Groups and Women Empowerment, Sahoo R.K, Tripathy S.N, Anmol Publications Pvt. Ltd., New Delhi pp.56-78.
Ramesh CP (2006), "Women SHGs in Orissa - a Crusade for Women Empowerment", Self Help Groups and Women Empowerment, Sahoo R.K, Tripathy S.N, Anmol Publications Pvt. Ltd., New Delhi pp.44-45.

Sakuntala N (2005). Empowering Women: An Alternative Strategy from Rural India, Sage Publications, New Delhi. pp. 24-34.

Sudha N (2008). Women's Empowerment in South Asia, Navayug Publishers and Distributors, New Delhi. pp. 63-67.

Susanta KP, Manas RP, Rama KD, Subash CM (2007). WSHG: A Vehicle for Women Self Reliance, Retrieved from www.iceg.net/2007/books on 30 June 2009.

Sreedaya GS, Kumari S, Nehru SM (2001). Perception of officials about self help groups involved in vegetable cultivation. J. Trop. Agric. 39(1):87

Umesh CP (2006). "Significance of Women Empowerment and Rural Credit in Orissa Through SHGs", Self Help Groups and Women Empowerment, Sahoo R.K, Tripathy S.N, Anmol Publications Pvt. Ltd., New Delhi. pp. 21-26.

Zubair M (2003). Empowering Rural Women: An Approach to Empowering Women through Credit-Based Self Help Groups, Aakar Books, Delhi pp.75-96. 